\title{
Loucura e Trabalho no Encontro entre Saúde Mental e Economia Solidária
}

Madness And Work In The Articulation

Of Mental Health And Solidarity Economy

Locura Y Trabajo En El Encuentro Entre Salud Mental Y Economía Solidaria

Márcia Campos Andrade, Maria Aparecida de Moraes Burali, Aline Vida, Michely Balladeli B. Fransozio \& Raquel Zavatin dos Santos

Universidade Estadual de Maringá

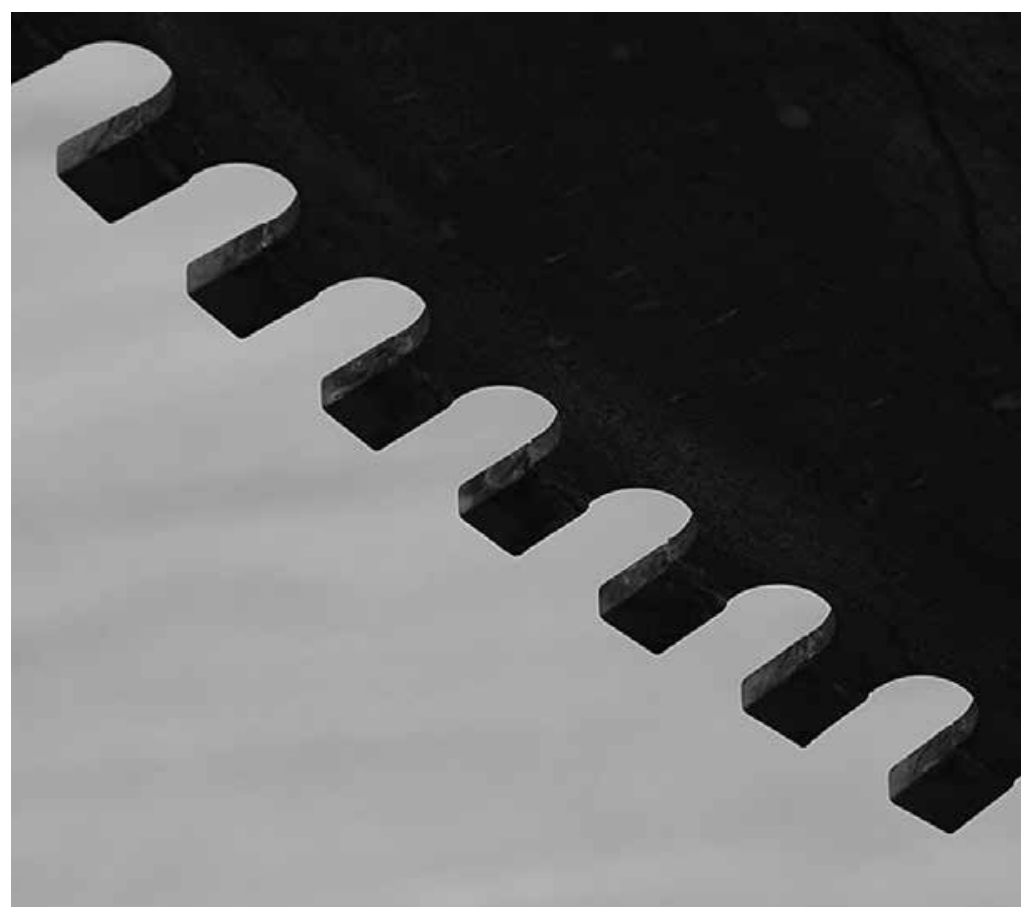


Resumo: A relação entre loucura e trabalho, no contexto da articulação saúde mental e economia solidária na elaboração de uma política pública intersetorial de inclusão social pelo trabalho, em curso desde 2004, é o tema de interesse deste relato de pesquisa realizado em dois momentos - pesquisa bibliográfica e pesquisa de campo. A pesquisa bibliográfica teve como foco os temas trabalho, exclusão/inclusão e subjetividade. Realizou-se a análise de documentos da reforma psiquiátrica, da economia solidária, da articulação desta com a saúde mental e o levantamento das experiências em curso no Brasil. A pesquisa de campo foi realizada em um Centro de Atenção Psicossocial (CAPs), através do Dispositivo Intercessor, como práxis de intercessão visando a constituir uma iniciativa de inclusão social pelo trabalho. Esta pesquisa gerou reflexões a respeito do entrelaçamento entre a loucura e o trabalho em relação às formas, ao significado e ao impacto deste último na vida dos que buscam inclusão social. Na articulação saúde mental e economia solidária, pode-se observar que existe uma centralidade do trabalho onde a este são atribuídos significados como recurso terapêutico, direito humano, produtor de subjetividade e possibilidade concreta de cidadania e de emancipação como instrumento de inclusão social.

Palavras-chave: Loucura. Trabalho. Saúde mental. Economia solidária.

Abstract: The connection between madness and work in the context of mental health and solidarity economy in the establishment of an intersectorial public policy for social inclusion through work, in current development since 2004, is the main focus of this research account which was carried out through two different proceedings: bibliographical and field research. The bibliographical research focused on work, exclusion/inclusion and subjectivity. The documents that were analyzed derived from psychiatric reform, solidarity economy and its articulation with mental health, as well as a study of the current experiences in Brazil. The field research was conducted in a Psychosocial Healthcare Center (CAPs) through the Intervenient Mechanism as an intervention praxis in constituting a social inclusion initiative through work. This research brought out some reflections on the intertwining of madness and work concerning the ways and meaning and the impact of the latter for the lives of those people who seek social inclusion. In the mental health and solidarity economy articulation it was realized that there is a centrality of work when it means a therapeutic resource, human rights, builder of subjectivity, and a great possibility of citizenship and empowerment as an instrument for social inclusion.

Keywords: Madness. Work. Mental health. Solidarity economy.

Resumen: La relación entre locura y trabajo, en el contexto de la articulación salud mental y economía solidaria en la elaboración de una política pública intersectorial de inclusión social por el trabajo, en curso desde 2004, es el tema de interés de este relato de investigación realizado en dos momentos - investigación bibliográfica e investigación de campo. La investigación bibliográfica tuvo como centro los temas trabajo, exclusión/inclusión y subjetividad. Se realizó el análisis de documentos de la reforma psiquiátrica, de la economía solidaria, de la articulación de esta con la salud mental y el relevamiento de las experiencias en curso en Brasil. La investigación de campo fue realizada en un Centro de Atención Psicosocial (CAPs), a través del Dispositivo Intercesor, como praxis de intercesión visando constituir una iniciativa de inclusión social por el trabajo. Esta investigación generó reflexiones al respecto del entrelazamiento entre la locura y el trabajo con relación a las formas, al significado y al impacto de este último en la vida de los que buscan inclusión social. En la articulación salud mental y economía solidaria, se puede observar que existe una centralidad del trabajo en donde a éste le son atribuidos significados como recurso terapéutico, derecho humano, productor de subjetividad y posibilidad concreta de ciudadanía y de emancipación como instrumento de inclusión social.

Palabras clave: Locura. Trabajo. Salud mental. Economía solidaria.

O tema de interesse deste artigo é a relação entre loucura e trabalho no contexto brasileiro da saúde mental em sua articulação com a economia solidária na elaboração de uma política pública intersetorial de inclusão social pelo trabalho. $\mathrm{O}$ artigo tem como objetivo construir, sucintamente, um cenário sobre esse tema no contexto sociohistórico da reforma psiquiátrica brasileira, através da realização de pesquisa bibliográfica e da reflexão sobre a experiência de constituição de uma iniciativa de inclusão social pelo trabalho a partir da pesquisa de campo realizada em um CAPs I através do Dispositivo Intercessor. Sendo um tema incipiente no cenário brasileiro, configurase como um campo multirreferenciado de pesquisa que demanda a participação da 
Universidade como instância de produção de conhecimento, contribuindo com a análise e a reflexão crítica sobre as temáticas a ele pertinentes; além disso, carece de discussão política a respeito do direito humano ao trabalho dos sujeitos da experiência da loucura atendidos pelos serviços de saúde mental.

A questão do trabalho é um dos eixos da reforma psiquiátrica brasileira junto à retaguarda assistencial através dos Centros de Atenção Psicossocial (CAPs), a retaguarda de moradia através do Sistema de Residências Terapêuticas e de reparação econômica através do programa De Volta para Casa.

O evento I Oficina Nacional de Experiências de Geração de Renda e Trabalho de Usuários de Serviços de Saúde Mental (Brasil, 2005b), realizado em 2004, é o marco histórico da constituição da Política Intersetorial de Saúde Mental e Economia Solidária. Tal política é resultante da articulação entre a Coordenação de Saúde Mental, Álcool e Outras Drogas, do Ministério da Saúde, e a Secretaria Nacional de Economia Solidária, do Ministério do Trabalho e Emprego.

Esse evento teve como objetivo construir as bases dessa articulação com o foco na inclusão social pelo trabalho de usuários dos serviços de saúde mental com transtornos mentais graves ou decorrentes do uso de álcool e de outras drogas por meio da constituição de empreendimentos econômicos solidários, que podem ser grupos informais, associações e/ou cooperativas (Brasil, 2005b). Como encaminhamento, foi criado, através da Portaria Interministerial no 353, de 7 de março de 2005 (Brasil, 2005c), o Grupo de Trabalho Saúde Mental e Economia Solidária. Algumas das ações propostas no relatório do GT estão sendo desenvolvidas, como a formação em saúde mental e economia solidária dos usuários, familiares e trabalhadores da saúde mental, o mapeamento nacional das iniciativas de geração de trabalho e renda, a constituição de redes, entre estas, a realização e a participação em feiras de economia solidária com atividade de trocas com o uso de moeda social.

Os dispositivos institucionais da Política Nacional Intersetorial de Saúde Mental e Economia Solidária: Inclusão Social pelo Trabalho são a Rede Brasileira de Saúde Mental e Economia Solidária e o Cadastro de Iniciativas de Inclusão Social pelo Trabalho (CIST), do Ministério da Saúde.

A rede é constituída pelas iniciativas de geração de trabalho e renda, por entidades de apoio, como a Incubadora Tecnológica de Cooperativas Populares da Universidade Federal do Rio de Janeiro (ITCP/COPPE/ UFRJ), e gestores públicos das políticas de saúde mental e de economia solidária. A rede construiu, através do mapeamento previsto pelo GT, um banco de dados das iniciativas de geração de trabalho e renda.

O CIST, que no final de 2010 contava com a inscrição de 640 iniciativas de inclusão social pelo trabalho no Portal da Saúde Mental do Ministério da Saúde, tem como objetivo subsidiar as ações da política pública e fomentar a interação entre as iniciativas cadastradas.

Consideramos importante observar a existência de duas formas de nomear as experiências em curso: iniciativas de geração de trabalho e renda (Rede Brasileira) e iniciativas de inclusão social pelo trabalho (CIST). Outras formas são as de empreendimentos de saúde mental e economia solidária e de cooperativas sociais. Talvez essas nomeações reflitam o atual momento de construção dessa política e a singularidade da realidade social onde é desenvolvida, bem como as diferentes concepções existentes a respeito da relação entre loucura e trabalho.

Esse é o contexto sociohistórico da pesquisa teórico-prática da qual trata este artigo, 
Na década de 40, a terapêutica ocupacional de Nise da Silveira via o trabalho como um recurso terapêutico tão importante como os demais. Na reforma psiquiátrica, a partir da década de 80, o trabalho passa a ser um instrumento de reabilitação e de (re)inserção social, e cria novas inscrições da loucura na cultura e na cidadania (Guerra, 2008). que foi desenvolvida através de um projeto realizado em dois momentos, sendo o primeiro um estudo teórico, concluído em 2009, e o segundo, uma pesquisa de campo, concluída no final de 2011.

A relação entre loucura e trabalho sofreu várias mudanças ao longo da História, tanto nas concepções a ela atribuída como nas práticas produzidas a partir dessas concepções. $\mathrm{Na}$ assistência leiga das instituições filantrópicas, o trabalho teve a função de auxiliar na manutenção da ordem social e econômica; no nascimento da psiquiatria, com o tratamento moral e asilar, teve uma função disciplinadora na busca para curar a loucura (Foucault, 2003); na reforma psiquiátrica francesa, é instrumento terapêutico de ressocialização, e, na italiana, compõe o projeto de emancipação terapêutica como um operador de inserção social (Passos, 2009). No Brasil, nas Colônias Agrícolas da década de 20, era uma imposição terapêutica do tratamento moral. Na década de 40 , a terapêutica ocupacional de Nise da Silveira via o trabalho como um recurso terapêutico tão importante como os demais. Na reforma psiquiátrica, a partir da década de 80 , o trabalho passa a ser um instrumento de reabilitação e de (re)inserção social, e cria novas inscrições da loucura na cultura e na cidadania (Guerra, 2008).

Pode-se ver, então, que a relação entre trabalho e loucura é mais antiga do que se possa imaginar. Pode-se considerar, também, que as crenças e as práticas relacionadas à concepção de loucura de uma determinada sociedade produzem modos de pensar e de agir em relação a essa que culminam na criação de instituições configuradas como espaços que oferecem tratamento, limites, normas pautadas pela lógica vigente nessa sociedade, que também produz uma concepção de relação entre loucura e trabalho.
Entretanto, movimentos de contraposição são engendrados pelos que sofrem o instituído normatizador estabelecido pelo tratamento moral da ciência psiquiátrica, em que o trabalho foi destituído de seu valor de produção e passou a ser imposto com regra moral pura, com o objetivo de limitar a liberdade, submeter à ordem e desalienar o espírito (Foucault, 2003). Nesse sentido, se a sociedade moderna e sua instituição asilar tiveram uma função vital no estabelecimento de uma consciência ética que acreditava que o trabalho fosse o principal eixo regulador da sociedade, os loucos marcaram sua diferença ao resistirem em submeter-se às regras inerentes à concepção de trabalho estabelecida pelo tratamento moral no asilo.

Nessa perspectiva, movimentos de resistência engendrados no século XX provocaram grandes transformações no âmbito da psiquiatria em vários países, como, por exemplo, a psicoterapia institucional e a psiquiatria de setor, na França, a Reforma Psiquiátrica Democrática Italiana, o Movimento Nacional da Luta Antimanicomial e a reforma psiquiátrica, no Brasil. Esses têm forjado um repensar a respeito do lugar do louco na sociedade e das formas de atenção e cuidado que desconstruam a lógica manicomial.

Os ideários da luta pela reforma psiquiátrica no Brasil nascem com o Movimento da Reforma Sanitária, na década de 70. Entretanto, essa é engendrada a partir de 1987, com o início dos movimentos sociais a favor dos direitos dos pacientes psiquiátricos, que culminou com a criação do Movimento Nacional da Luta Antimanicomial, constituído pelo Movimento dos Trabalhadores em Saúde Mental (MTSM), associações de familiares, sindicalistas, membros de associações de profissionais e pessoas com longo histórico de internações psiquiátricas. A denúncia dos maus tratos e do poder da rede privada de assistência foi o foco principal dos direitos buscados nesses movimentos. 
Em 1989, entra na cena da luta antimanicomial brasileira o projeto de lei do deputado federal Paulo Delgado (PT/MG), que visava a uma regulamentação dos direitos das pessoas portadoras de sofrimento psíquico e a extinção progressiva dos manicômios no País. Inspirados por esse projeto, o Movimento Nacional da Luta Antimanicomial conseguiu a aprovação para as primeiras leis que pretendiam substituir os leitos psiquiátricos por uma rede integrada de atenção à saúde mental. O compromisso firmado pelo Brasil na assinatura da Declaração de Caracas e a realização da II Conferência Nacional de Saúde Mental, ambas ocorridas na década de 90, fizeram que fossem implantados serviços de atenção diária e normas para a fiscalização e a classificação dos hospitais psiquiátricos.

Em 2001, é então aprovada a lei proposta por Paulo Delgado em 1989, agora com o número 10.216, que privilegia o tratamento em serviços de atenção psicossocial em base comunitária, dispondo da proteção e do direito às pessoas portadoras de sofrimento psíquico. O período atual caracteriza-se, assim, por dois movimentos simultâneos: a construção de uma rede de atenção à saúde mental substitutiva ao modelo hospitalocêntrico, por um lado, e a fiscalização e a redução progressiva e programada dos leitos psiquiátricos existentes, por outro.

Nesse contexto, as mudanças relacionadas à maneira de se referir ao louco aconteceram na medida em que se percebeu a importância da desconstrução do estigma de que o louco é um sujeito incapaz tanto de governar sua vida como de trabalhar. Os movimentos de reformas psiquiátricas que aconteceram em vários países visavam justamente a modificar a forma de tratamento destinado aos sujeitos da experiência da loucura, eliminando gradualmente o internamento com a construção de dispositivos na comunidade substitutivos à lógica manicomial e procurando a desinstitucionalização e a reabilitação psicossocial.
(...) o trabalho de desinstitucionalização leva, necessariamente, à produção de um novo tipo de subjetividade, que permita a manifestação do devir-louco sem interditar sua expressão, sem regulá-lo no jogo das sanções institucionais e legais ou objetificálo, fazendo com que se desistorize e deixe de ser um sujeito. É a produção de um novo lugar para a subjetividade louca, o estabelecimento de uma nova relação com ela, e a criação de fissuras na serialização psiquiátrica. Para isso, é preciso a tomada de um sentido para a própria existência e da produção de sua própria singularidade (Amarante \& Torre, 2001, p. 82)

Os movimentos das reformas psiquiátricas, em especial a italiana e a brasileira, concebem a pessoa em sofrimento psíquico como sujeito desejante que participa politicamente e constrói projetos, sujeito capaz de se inserir na sociedade e no mundo do trabalho. Entretanto, o trabalho como possibilidade de inserção do louco no mundo do intercâmbio, ou seja, das trocas sociais que produzem e reproduzem a vida, é recente tanto nos documentos relacionados à reforma psiquiátrica como no cotidiano da maioria dos serviços de saúde mental no Brasil.

Além disso, as transformações em curso no mundo do trabalho desde o final do século XX colocaram uma grande parte da população economicamente ativa em situação de desemprego ou de subemprego e promoveram profundos impactos na saúde mental dos trabalhadores assalariados, portadores ou não de sofrimento psíquico.

É nesse contexto que se configura no Brasil um movimento de ruptura com o modo de produção capitalista denominado economia solidária, pautado por valores de autogestão e de solidariedade nas relações de trabalho e que tem como centralidade o ser humano, a natureza e a relação de sustentabilidade entre esses. É interessante notar que tanto o movimento da luta antimanicomial como o movimento da economia solidária preconizam 
a construção de outro projeto de sociedade, compartilhando princípios fundamentais pautados em dimensões éticas, políticas e ideológicas que preconizam uma sociedade de solidariedade e de justiça, ou seja, ambas se contrapõem ao projeto capitalista de sociedade.

A economia solidária pode ser entendida, de acordo com Singer (2003), como o conjunto de atividades econômicas - de produção, comercialização, consumo, poupança e crédito - organizadas sob a forma de autogestão, isto é, pela propriedade coletiva do capital e pela participação democrática (uma cabeça, um voto) nas decisões dos membros da entidade promotora da atividade. Segundo o mesmo autor, o desenvolvimento da economia solidária no Brasil acontece a partir da década de 80 com a contrarrevolução neoliberal. O aumento dos níveis mundiais de desemprego nas últimas décadas do século $\mathrm{XX}$ teve como uma de suas principais consequências o incremento do trabalho informal como geração de renda, de sobrevivência material e de manutenção de espaços de trabalho, mesmo em condições precárias. Como outra forma de organizar o trabalho através da autogestão e da solidariedade, a economia solidária emerge como estratégia coletiva de alternativa ao desemprego e à precarização do trabalho.

No contexto da articulação saúde mental e economia solidária, pode-se observar a existência da centralidade do trabalho, sendo esse um meio de interlocução entre essas duas políticas públicas. Nesse sentido, discutiremos as dimensões do trabalho como recurso terapêutico, como direito humano, como produtor de subjetividade e como possibilidade concreta de cidadania e de emancipação como instrumento de inclusão social dos usuários dos serviços.

Interessa-nos discutir e refletir a respeito da possibilidade concreta de trabalhadores, sujeitos da experiência da loucura que possuem uma história marcada por internações em hospitais psiquiátricos, terem o direito de trabalhar, assumindo, assim, sua condição de cidadãos nas relações de produção e de reprodução da vida pela via da convivência social e do trabalho como atividade no mundo das trocas simbólicas e materiais, e não somente para o cuidado de si mesmo, como um recurso terapêutico.

Sendo assim, é preciso contemporizar a precariedade ainda existente no campo das políticas públicas de saúde mental e de trabalho no âmbito da economia solidária, e, em especial, ao direito dos sujeitos da experiência da loucura de trabalhar de maneira coletiva e autogestionária. Atualmente, a condição de inclusão social pelo trabalho desses é regida pela Lei $\mathrm{n}$ 은 9.867, de 10 de novembro de 1999 (Brasil, 1999), que regulamenta o funcionamento das cooperativas sociais como modalidade de trabalho dos que estão em situação de desvantagem social, caracterizando-o como um trabalho assistido em que a autonomia do trabalhador é mediada pela assistência que Ihe é oferecida pelo Estado.

\section{Metodologia}

Tendo como referência metodológica a pesquisa qualitativa em Minayo (1994), através da análise de conteúdo (temática) e do levantamento de categorias de análise como modalidade de análise qualitativa, foi realizada a pesquisa bibliográfica em livros e artigos publicados tendo como critério algumas categorias de análise construídas a priori, que são: trabalho, exclusão/inclusão, subjetividade. Com isso, construiu-se um referencial teórico com as contribuições da Psicologia social comunitária, da esquizoanálise e da Sociologia crítica para a análise de conteúdo dos documentos relacionados ao tema deste artigo. 
Foram analisados documentos da reforma psiquiátrica brasileira sobre o trabalho como recurso terapêutico e como um direito humano, da economia solidária sobre o trabalho coletivo, solidário e autogestionário, e da articulação saúde mental e economia solidária com foco nas experiências existentes.

Foram levantadas informações sobre o banco de dados das iniciativas de geração de trabalho e de renda através do Portal da Rede de Empreendimentos de Saúde Mental e Economia Solidária e do Cadastro de Iniciativas de Inclusão Social pelo Trabalho (CIST), do Ministério da Saúde.

Com isso, buscou-se conhecer os sentidos atribuídos ao trabalho tanto na saúde mental como na economia solidária e as práticas existentes no Brasil na articulação entre essas políticas públicas.

No segundo momento, foi realizada uma pesquisa de campo em um Centro de Atenção Psicossocial localizado em uma cidade no noroeste do Paraná, através do DI - Dispositivo Intercessor (Costa-Rosa, 2008), que contribuiu com a constituição de uma experiência em saúde mental e economia solidária. O DI produz duas inscrições: como práxis de intercessão, que acontece no campo psicossocial da pesquisa, e, como meio de produção de conhecimento, que acontece após a saída do intercessor do campo da intercessão.

No presente artigo, trataremos do DI como práxis de intercessão, configurado nas oficinas de geração de trabalho e renda realizadas no Centro de Atenção Psicossocial (CAPs). Nesse caso, somente serão apresentados os recursos metodológicos utilizados na pesquisa de campo e os resultados referentes à produção de uma práxis de pré-incubagem de iniciativas de inclusão social pelo trabalho partindo do interesse dos participantes. Essa se configura como uma oferta de possibilidade que pode vir a ser uma ferramenta de trabalho para a equipe do CAPs na realização das oficinas de geração de trabalho e renda, que são um dos dispositivos que compõem o projeto terapêutico dos que são atendidos na Atenção Psicossocial.

O DI tem como referências teóricometodológicas o materialismo histórico, a psicanálise lacaniana, a análise institucional e a esquizoanálise (Costa-Rosa, 2008), e, como é uma metodologia de pesquisa em construção, faz-se necessário um esclarecimento sobre o conceito de intercessor a partir da esquizoanálise em Deleuze (1992). O intercessor é alguém demandado a participar dos processos de reflexão e de transformação de um coletivo, produzindo nele sua participação não como um especialista (consultor, assessor, psicólogo ou mesmo restrito à função de pesquisador), mas como alguém que desliza no movimento desse coletivo sem ser o agente e nem a referência desse movimento, embora possa, com sua ação como um de seus integrantes, suscitar a reflexão coletiva que desencadeie o movimento.

O DI como intercessão toma a noção de campo como o território da realidade concreta e da intersubjetividade onde se dá a prática psicossocial dos sujeitos que compõem esse território. O DI vai para além da intervenção, porque sua ação não se esgota no campo da intercessão (produzido pelos próprios sujeitos que nele estão ao endereçarem ao intercessor uma demanda de transformação em sua prática cotidiana), mas estende-se à produção de conhecimento sobre sua ação nesse campo.

As ferramentas de pesquisa, advindas da análise institucional e da esquizoanálise, são: o diário de campo (Lourau, 2004), como guia para a ação no campo da intercessão e para a elaboração teórica a partir da análise de implicação do intercessor, a análise da implicação (Paulon, 2005), que se refere aos 
lugares que o intercessor ocupa no campo da intercessão e o seu envolvimento pessoal com o mesmo, bem como dos jogos de interesse e de poder presentes nesse campo, dos quais o intercessor também participa, e a cartografia dos afetos (Rolnik, 2007), como maneira de entender as estratégias de formação do desejo no campo da intercessão, que inventa ações contextualizadas tanto nesse como em sua sensibilidade ao se relacionar com os que dele participam.

A ferramenta de intercessão no campo foi a Oficina de Geração de Trabalho e Renda (OGTR), uma prática clínica e social dos serviços de saúde mental que tem como objetivo o trabalho produtivo com vistas às trocas econômicas e sociais, que foram iniciadas no dia 24/08/2011 e terminaram no dia 16/12/2011, e, durante esse período, foram realizadas 31 (trinta e uma) OGTRs. O caminho foi sendo construído no contexto das possibilidades existentes em cada momento da oficina e através da escuta das histórias de vida de trabalho e de outras, assim como das ideias sobre atividades produtivas que poderiam ser desenvolvidas.

Nas primeiras oficinas, participaram de sete a onze pessoas atendidas pelo CAPs; o grupo era aberto aos que estivessem interessados em participar e, com o tempo, configurou-se como um processo grupal em torno da dimensão trabalho e da possibilidade de vir a ser um trabalhador, de desenvolver uma atividade produtiva sem ser empregado de alguém e gerar alguma renda para si mesmo. Tal questão demarcou a identificação de alguns com o projeto e a desistência de outros, e, no final do processo, quatro pessoas que participaram ativamente se organizaram coletivamente para a constituição de um projeto de geração de trabalho e renda - o Arte em Oficina, desenvolvido dentro do CAPs - onde estão produzindo e comercializando ganchos para lona de caminhão.

\section{Resultados}

Através da leitura e da análise do material bibliográfico sobre o tema, encontramos alguns conceitos que produziram núcleos de sentido sobre a relação entre loucura e trabalho na articulação entre a saúde mental e a economia solidária. Deve-se dizer que tais conceitos não são autorais, mas a sua definição como categorias de análise e eixos de discussão sobre o tema, sim.

O conceito de subjetividade surge como matéria-prima viva e em constante mudança com a qual se pode vivenciar, experimentar, conhecer e inventar formas de agir e de se relacionar tanto com o mundo de dentro como com o mundo de fora (Guattari \& Rolnik, 1986). Tal concepção preconiza a produção de sujeitos como um processo, e não como uma finalidade em si em que se pode realizar o intercâmbio entre o mundo da assistência, como o cuidado de si - do mundo de dentro - com o mundo da produção - o de fora - na perspectiva da economia solidária.

No sentido de se entender a subjetividade como produção, outros conceitos apontam uma perspectiva mais contextualizada à experiência da loucura ao respeitar sua singularidade: 1) subjetividade de fronteira, como um espaço de inovação e de instabilidade onde se tem que inventar outras formas de conviver, que criar uma transparência entre os atos e suas consequências, que reconhecer na diferença entre estranhos a oportunidade de enriquecimento mútuo e de participação através do princípio da comunidade (Santos \& Meneses, 2010, pp. 347-356), 2) subjetividade barroca, que tem a marca da mestiçagem entre várias formas culturais, religiosas e sociais, em que as múltiplas combinações descaracterizam um poder central, sendo o local sua espacialidade e o imediato sua temporalidade, onde tem lugar o particular, o efêmero e o transitório (Santos \& Meneses, pp. 356-367), 3) 
subjetividade do sul, por ser esse o lugar privilegiado para a reinvenção das energias emancipatórias e da subjetividade da pós-modernidade a partir das práticas de solidariedade e de reciprocidade. O sul representa a relação de subordinação sociocultural e socioeconômica dos grupos, etnias, culturas, países que são oprimidos, expropriados, suprimidos, silenciados e tratados a partir de uma diferenciação desigual pelos que detêm o poder no sistema capitalista mundial (Santos \& Meneses, pp. 367-380).

Sobre a articulação entre saúde mental e economia solidária, operamos com os conceitos de trabalho emancipado e de exclusão, além de algumas categorias de análise construídas a partir da leitura e da análise dos documentos sobre o tema.

\section{O conceito de trabalho emancipado} (cooperativo, solidário e autogestionário) é caracterizado por uma perspectiva ontológica do trabalho, pela qual se pretende superar sua condição de mera garantia da sobrevivência material, retomando sua condição de satisfazer as necessidades humanas de vida, comunidade, reciprocidade e solidariedade (Arruda, 2003). Consideramos ser essa a concepção de trabalho que pode contribuir com a articulação entre a saúde mental e a economia solidária produzindo uma necessária reflexão e mudança sobre as concepções de trabalho terapêutico, trabalho assistido e trabalho protegido, ainda vigentes nos dispositivos de saúde mental no Brasil.

O conceito de exclusão seria o descompromisso político com o sofrimento do outro e a introdução da ética e da subjetividade na análise sociológica da desigualdade social para além das interpretações legalistas e minimalistas de inclusão, como as baseadas em justiça social e restritas à crise do Estado e do sistema de empregabilidade (Sawaia, 2006). Sendo o processo de inclusão o eixo estruturante da articulação saúde mental e economia solidária, é preciso fazer uma análise crítica a respeito da concepção de exclusão que sustenta as atuais práticas de inclusão.

$\mathrm{Na}$ análise dos documentos Relatório Final da III Conferência Nacional de Saúde Mental/ Reorientação do Modelo Assistencial em Saúde Mental/Desinstitucionalização/ Trabalho e Geração de Renda (Brasil, 2002, p.45), constatou-se que os participantes do evento apontaram duas perspectivas de inserção no mundo do trabalho: 1) através do emprego formal, quando se propõe o incentivo às empresas para contratar usuários dos serviços de saúde mental através do sistema de quotas, e 2) através de ações de geração de renda a partir do trabalho associativo e cooperativo como parte integrante do cuidado em saúde mental, garantindo que cada NAPS/CAPs desenvolva oficinas de produção sistemática, visando à profissionalização do trabalho com remuneração para os usuários.

Entretanto, a compreensão do trabalho associativo e cooperativo como economia solidária somente aconteceu em 2004, durante o evento Oficina de Experiências de Geração de Renda e Trabalho dos Usuários dos Serviços de Saúde Mental, que resultou na publicação Saúde Mental e Economia Solidária: Inclusão Social pelo Trabalho (Brasil, 2005b). Nessa publicação, analisamos os relatos dos participantes da mesa-redonda Experiências de Geração de Renda e Trabalho e construímos as seguintes categorias de análise que também foram discutidas em Andrade (2010, pp. 255-256):

\section{o relacionamento com o mercado} capitalista, no contexto do mundo do trabalho na reorganização produtiva com sua conjuntura econômica, produz o aparecimento de outra concepção de mercado diferente da instituída pelo capitalismo. Nessa, a expectativa relacionada ao fato de que trabalhar é ter um emprego é colocada 
em questão a partir da possibilidade de inclusão no mundo do trabalho através do cooperativismo e da participação em feiras da economia solidária. Outra questão importante é a qualidade do trabalho realizado pelos que participam dos projetos, que torna seus produtos interessantes para os seus possíveis consumidores;

o destaque à organização do trabalho autogestionário na perspectiva da economia solidária como alternativa possível a partir de práticas nos serviços de saúde mental em que há a participação de todos nas decisões sobre a escolha da atividade produtiva a ser desenvolvida, no consumo da matériaprima, no processo de produção e na comercialização dos produtos, assim como no pagamento dos custos e na distribuição das sobras;

a questão de ser aposentado ou de receber algum benefício social como um direito, mas também como marca da incapacidade para o trabalho, em que voltar a trabalhar implica deixar de receber recursos relacionados a essa condição. Além disso, existe a vulnerabilidade das iniciativas associadas aos problemas de gestão, de falta de infraestrutura, da carga tributária e ao fato de os participantes não serem proprietários dos equipamentos com os quais trabalham, o que demanda ações de apoio a essas iniciativas pelas políticas de saúde mental e economia solidária;

o relacionamento entre o capitalismo e o manicômio produz, historicamente, o estranhamento diante da diferença e a exclusão dos diferentes da sociedade e, em consequência, da condição de trabalhador;

- a concepção e a organização de trabalho do projeto antimanicomial seria, como sobrevivência material e de produção em massa, imposta como tratamento ou uma estratégia de construir junto o direito de trabalhar e de se inscrever subjetivamente no tecido social, indo além da sobrevivência?

Nos documentos Conferência Regional de Reforma dos Serviços de Saúde Mental: 15 anos depois de Caracas (Brasil, 2005a) e Relatório de Gestão 2003-2006 (Brasil, 2007), encontramos citações do evento de 2004 como um marco da articulação saúde mental e economia solidária, e, a partir disso, houve a criação de dispositivos institucionais como: o Programa de Inclusão Social pelo Trabalho, assumido pelos Ministérios do Trabalho e Emprego e Saúde, o Grupo de Trabalho de Saúde Mental e Economia Solidária e uma linha específica de financiamento destinada aos Municípios que desenvolvem atividades de inclusão econômica de pessoas com transtornos mentais (PT GM no 1.169/05), impulsionando efetivamente essas iniciativas, além de colocar na pauta da discussão jurídica e política a Lei das Cooperativas Sociais (Lei Federal no 9.867/1999) (Brasil, 1999).

Alguns eventos ligados à temática deste artigo aconteceram após o encerramento do estudo teórico e serão acrescentados à análise, por serem parte constituinte do processo sociohistórico de construção dessa política pública intersetorial, através de seus documentos, que são o Relatório Final da IV Conferência Nacional de Saúde Mental (Brasil, 2010) e o Caderno da Conferência Temática de Cooperativismo Social, realizadas em 2010 (Brasil, 2010).

No primeiro documento, a questão da inclusão social pelo trabalho está relacionada aos direitos humanos e à cidadania como desafio ético e intersetorial através da discussão sobre o trabalho, a geração de renda e a economia solidária. As possibilidades de trabalho tanto no mercado formal quanto em projetos de geração de trabalho e renda são mantidas como eixos de inclusão, sendo a articulação intersetorial entre as políticas públicas a estratégia para a promoção do direito de trabalhar através do financiamento 
das iniciativas e da qualificação e da inclusão digital de seus trabalhadores. No que se refere à articulação com a economia solidária, a ênfase foi dada à Política de Economia Solidária e Inclusão Social e ao Programa Nacional de Cooperativismo Social, que ainda não constavam no relatório da III Conferência de 2001 (Brasil, 2010a).

No segundo documento, reafirma-se a dimensão da intersetorialidade da estratégia de fomento e do apoio ao cooperativismo social pelas três esferas governamentais (Governo Federal, Estados e Municípios) através de três eixos temáticos: o marco conceitual, que define as pessoas em situação de desvantagem como as que se organizam a partir do cooperativismo social, o marco jurídico, com propostas de revisão da Lei das Cooperativas Sociais, e as políticas públicas, com a proposição de que o cooperativismo social seja considerado uma política de Estado (Brasil, 2010b).

A partir da análise dos documentos e do material bibliográfico, foi possível compreender o significado e o impacto do trabalho na vida dos sujeitos da experiência da loucura e seu entrelaçamento com a dimensão da loucura no decorrer da História, na consolidação do capitalismo como modo de produção e modelo de sociedade, na relação com o Estado, com a ciência e com o Direito.

De acordo com Zambroni-de-Souza (2006), os usuários dos serviços de saúde mental querem muito mais do que o acesso terapêutico, querem ter o direito ao trabalho e, com ele, a possibilidade de reconhecimento, de autonomia e de remuneração. Entretanto, o autor questiona se as tentativas de trabalho vinculadas aos serviços de saúde mental têm possibilitado a reinserção desses indivíduos ao mercado de trabalho, se elas transpõem de fato a atividade ocupacional, cuja função é estritamente terapêutica.
Sabemos que tanto as experiências de geração de trabalho e renda pelos usuários dos serviços de saúde mental como o trabalho autogestionário nos empreendimentos de economia solidária são construídas no contexto de uma história de lutas políticas contra a exclusão social dentro da sociedade capitalista. Sabemos também que existe um conjunto legitimado de práticas emancipatórias em seus espaços de referência e a institucionalização dessas práticas através de políticas públicas consolidadas e em vias de implantação.

Entretanto, o encontro entre a saúde mental e a economia solidária carece de construção de referenciais teórico-metodológicos e tem lugar em uma sociedade ainda marcada pela lógica manicomial e pelo modo de produção capitalista que estão presentes em todos nós.

Esse encontro se dá, de maneira incipiente, como práticas clínicas e sociais nos serviços de saúde mental através das denominadas oficinas de geração de trabalho e renda, como no caso do CAPs Butantã, em São Paulo, das associações de usuários, familiares e trabalhadores, como no caso do Armazém das Oficinas na Associação Cornélia Vlieg, em Campinas, no Suricato - Associação de Trabalho e Produção Solidária - em Belo Horizonte, e da Associação Pró-Saúde Mental Trabalharte, em Juiz de Fora, que funciona em um centro de convivência, assim como em oficinas de trabalho solidário que são realizadas fora do espaço dos serviços, mas aliadas às políticas públicas de saúde mental, de saúde do trabalhador e de economia solidária,/ como o Geração Poá, em Porto Alegre.

Além desses, existem projetos abrigados em instituições hospitalares, como é o caso da Cooperativa da Praia Vermelha, no Hospital Pinel, no Rio de Janeiro, e a ATUT, uma associação de usuários e de pessoas da comunidade do entorno do Hospital São Pedro, em Porto Alegre. 
Outros projetos são desenvolvidos fora de espaços especificamente relacionados aos serviços de saúde mental, embora articulados a esses, como a Rede de Saúde Mental e Economia Solidária, na cidade de São Paulo, com a realização periódica de feiras e de mobilização e ação política pelo direito ao trabalho.

Muitas dessas experiências foram mapeadas no Banco de Dados do Portal da Rede de Empreendimentos de Saúde Mental e Economia Solidária e também inscritas no CIST - Cadastro de Iniciativas de Inclusão Social pelo Trabalho. Essas duas fontes de dados oferecem informações dos Estados e de seus Municípios, onde existem iniciativas com o nome, endereço, contato, telefone e e-mail e de seus produtos e serviços.

$\mathrm{Na}$ análise dessas informações, pode-se observar que os produtos e os serviços apresentam uma ampla diversidade, havendo, porém, uma predominância do artesanato, da coleta seletiva e da reciclagem, da confecção, de produtos alimentícios, da tecelagem e da marcenaria. Aparecem também atividades como serigrafia, trilhas ecológicas/turismo, lava-jato, jardinagem e produção de plantas medicinais, dentre outras. Foram encontradas iniciativas na grande maioria dos Estados brasileiros, com maior predominância nos Estados da Região Sudeste. As atividades aparecem, em sua maioria, no formato de oficina, e, com frequência, os locais de realização destas são os Centros de Atenção Psicossocial (CAPs) e os centros de convivência, que são dispositivos da política pública da reforma psiquiátrica.

Em relação às atividades produtivas desenvolvidas na articulação saúde mental e economia solidária, podemos considerar que essas não implicam atividades de produção industrial, e sim, de produção artesanal, agrícola, de prestação de serviços e de culinária, dentre outras. Por isso, não demandam compra de equipamentos e/ou de maquinários e de processos de capacitação para a relação homem-máquina, embora, muitas vezes, demandem processos de formação e de qualificação profissional.

No trabalho coletivo e autogestionário, a organização do trabalho e as ações de capacitação são advindas da escolha da atividade produtiva a partir da elaboração de um projeto coletivo fundamentado nas potencialidades dos que se interessam em participar de iniciativas de inclusão social pelo trabalho no contexto da articulação saúde mental e economia solidária.

Esse tipo de trabalho, portanto, pressupõe outra contratualidade social, diferente da estabelecida pelo trabalho no formato do emprego, o que implica a participação dos envolvidos nos processos decisórios e de gestão, sendo que, para isso, é preciso expressar-se, argumentar, dialogar e posicionar-se, na tentativa de busca do consenso e da atividade política da negociação, ou seja, é preciso experimentar o princípio da autogestão.

O vínculo entre os pares acontece pela via da construção de um projeto coletivo e pelo interjogo dos afetos e desafetos construídos e expressos pelas diversas possibilidades do existir humano. Além disso, a economia solidária possui um caráter ideológico, simbólico e concreto de organização do trabalho através da autogestão, caracterizado pela relação cotidiana com a alteridade do outro com o qual se compõe o empreendimento; portanto, existem dimensões societárias, políticas, econômicas, culturais, subjetivas e intersubjetivas a serem consideradas na construção desse projeto coletivo.

O início do processo de produção de uma práxis de pré-incubagem de empreendimentos de saúde mental e economia solidária no âmbito de oficinas de geração de trabalho e renda no CAPs de uma cidade de pequeno 
porte no noroeste do Paraná ocorreu através da realização de rodas de conversa com os interessados sobre a temática do trabalho.

As histórias contadas nessas rodas de conversa nos possibilitaram conhecer as experiências de trabalho de alguns e o incômodo da ausência deste na vida de outros, as situações de precariedade enfrentadas no trabalho e os seus impactos na saúde mental, muitas vezes sendo o pivô do acesso à aposentadoria por invalidez, e a realidade de quem nunca trabalhou como empregado e, ainda jovem, tinha expectativas de fazê-lo, considerando o risco de, com isso, perder o acesso ao benefício de prestação continuada.

Essas questões tão atuais e comuns ao ser humano somente aparecem porque esse dispositivo de atenção ao sofrimento psíquico o permite e faz-nos pensar a respeito da centralidade do trabalho nas vidas dessas pessoas, homens e mulheres adultos, sujeitos da experiência da loucura. Entretanto, ao se pensar no acesso ou no retorno a uma atividade de trabalho, a forma de concebêlo é a do emprego - acordar cedo todo dia, passar o dia trabalhando, chegar em casa cansado, ter um patrão que possa orientar e elogiar, receber o salário no final do mês, mas também ter que se submeter às ordens de quem manda, fazer as atividades sob a pressão do tempo, etc.

Nesse primeiro momento, não consideraram outras formas de trabalhar, sendo uma delas a de trabalhar junto, sem patrão, e de assumir tanto a produção como o planejamento e a gestão do próprio trabalho, e de, em vez de salário, dividir as sobras (termo usado no cooperativismo) depois de pagar todos os custos.

Foi preciso orientar os que se interessavam por essa perspectiva do trabalho coletivo (lembrando que o CAPs pode atender o interesse de inserção pelo emprego, mas que a contribuição na intercessão teve como foco a economia solidária). Começou-se pela construção de um possível projeto comum definindo-se qual seria a atividade produtiva (a partir das ideias de todos os que quiseram continuar), como e onde se daria a produção, quem seriam os fornecedores de matériaprima e os consumidores dos seus produtos. Essas são estratégias da economia solidária para provocar os participantes do grupo a se organizarem a partir dos seus interesses singulares na tentativa de encontrar um interesse comum e daí, quem sabe, levá-los a uma vinculação grupal mediada por uma tarefa coletiva - o trabalho para o intercâmbio -, produzindo, assim, um processo grupal que tem como foco a tarefa, e que não está centrado na figura do líder (Pichon-Rivière, 1988).

Outra questão interessante é que, ao se identificarem como trabalhadores, somente se viam como produtores, sem considerar as outras atividades-de compra de matéria-prima e equipamentos, de planejamento e gestão do empreendimento e de relacionamento com os consumidores, dentre outras - como suas, já querendo delegá-las aos que possuíam características de liderança no grupo e maior experiência como trabalhadores assalariados .

Para lidar com essa questão, foi preciso descentralizar a tarefa de se pensar e executar o projeto do empreendimento da figura da intercessora e do assistente social do CAPs que participou das oficinas desde o seu início. Essa é a estratégia da construção da autogestão pela via da prática cotidiana nas oficinas, destituindo-se o lugar do poder da autoridade do especialista e deixando-o vago para que possa ser ocupado. Entretanto, provoca-se a reflexão dos participantes sobre a importância de esse poder ser circulante, prevenindo a configuração da figura do chefe do grupo, o que colocaria em risco a autonomia e a participação ativa dos demais integrantes e a cristalização do projeto no formato do emprego. 
Partindo da premissa de que é preciso sonhar, ter ideias para realizar esse sonho e transformá-lo em um projeto a ser testado na realidade, toda a produção dos participantes relacionada aos seus sonhos, suas ideias e como transformá-los em realidade (através da identificação da matéria-prima, dos equipamentos necessários para concretizála e de quem seriam os possíveis clientes) foi registrada e anexada à parede da sala de oficinas do CAPs como um mosaico da sua produção coletiva realizado com a nossa colaboração, lembrando sempre que, em todas as possibilidades de atividade produtiva, estavam presentes as tarefas cotidianas de planejamento, produção e gestão coletiva do empreendimento. Depois disso, cada ideia foi discutida com a participação de todos a partir da realidade atual do grupo de concretizá-la, e foram criados por eles os critérios de escolha. Desse crivo, como um teste de realidade, ficaram duas ideias como atividades produtivas do grupo (produção de estopa e de gancho para lona de caminhão), fato que marcou o início de sua existência.

A concretude diária dessa produção, efetivada através desse mosaico na parede como um documento de uma história coletiva, contribuiu para a constituição do grupo e do vínculo entre seus participantes, assim como nos permitiu cartografar seu movimento e o nosso também, como intercessora.

No exercício da aprendizagem, o grupo segue tentando construir a autogestão e evitar sua serialidade. Definiram o nome e o slogan do projeto - Arte em Oficina: um projeto em ação coletiva - que serão os elementos identificadores do trabalho do grupo e a forma de apresentá-lo à equipe do próprio CAPs, aos moradores da cidade, aos fornecedores e aos possíveis consumidores.

O grupo está, no momento, negociando com a coordenação do CAPs sobre qual é o espaço físico que abrigará sua iniciativa de inclusão social pelo trabalho e a possibilidade de realizar, na cidade, a pesquisa de preço da matéria-prima necessária e o mapeamento da demanda de consumo de seus produtos.

Sendo assim, esse projeto está sendo construído como uma atividade desenvolvida pelo CAPs dentro do projeto terapêutico dos que dele participam, ou seja, ainda está no âmbito do trabalho assistido pelo poder local no contexto das políticas públicas de saúde mental e economia solidária.

É importante considerar que, nessas ações de inserção no tecido social através do trabalho coletivo e autogestionário, é possível experimentar a construção do que Rotelli, Leonardis e Mauri (1994) chamam de praça de mercado. Esta se configura como o território coletivizado onde se produz o intercâmbio, no âmbito da cidade, entre o mundo da assistência em saúde mental e o mundo da produção e da reprodução da vida. Nesse território, a questão da qualidade e não a da quantidade toma o lugar na cena do mercado como livre circulação de mercadorias, de afetos, de sociabilidade e de alteridade.

\section{Discussões e conclusões}

A produção de subjetividade do louco tem sua origem em bases históricas, éticas, políticas e conceituais, sendo que, para entendê-la, faz-se necessário compreender o contexto histórico no qual está inserido. Nesse sentido, vimos o percurso histórico do louco passar do alienismo e da psiquiatria, marcado pela incapacidade, pela irracionalidade e pela exclusão, para a construção do sujeito da luta antimanicomial e da reforma psiquiátrica, marcado pela "pulsão desejante, pela participação política e pela possibilidade de construir projetos" (Amarante \& Torre, 2001). Essas reflexões nos possibilitaram tecer entrelaçamentos entre a loucura e o trabalho e destes com a História, o capitalismo, o Estado, a ciência e o direito em relação 
às formas, ao significado e ao impacto do trabalho na vida dos sujeitos da experiência da loucura.

No contexto da articulação saúde mental e economia solidária, pode-se observar que existe a centralidade do trabalho, sendo esse um meio de interlocução entre essas duas políticas públicas. Nesse sentido, consideramos o trabalho um recurso terapêutico, um direito humano, como produtor de subjetividade e possibilidade concreta de cidadania e de emancipação como instrumento de inclusão social.

Em relação à produção de uma práxis de pré-incubagem de iniciativa de inclusão social pelo trabalho, no âmbito da Atenção Psicossocial, algumas questões precisam ser refletidas e contextualizadas na realidade social dessa pesquisa. Como se dará a relação desse projeto em curso com o CAPs que o abriga? Com os familiares dos que dele participam? Com a com a cidade onde moram? Com os empreendimentos econômicos solidários da região? Com o poder público local? Com a política estadual e nacional de saúde mental e de economia solidária?

Todas essas questões estão presentes no cotidiano dos sujeitos que participam do projeto e carecem de negociações e de inserções cada vez mais complexas, que serão realizadas na medida das possibilidades concretas de quem as empreende.

O processo de mudança provocado pelo trabalho no contexto da prática de constituição de uma iniciativa de inclusão social pelo trabalho pelos sujeitos da experiência da loucura é instigante e desafiador, mas também traz em seu bojo idiossincrasias que podem causar impacto na saúde e na vida desses sujeitos. Sabemos que as condições de trabalho desse grupo no início de suas atividades não são as melhores, mesmo porque, neste momento, ainda não é possível contar com o apoio mais efetivo de políticas públicas, mas com os próprios recursos do grupo, de seus familiares e do CAPs no acompanhamento de todo o processo, e os do poder local e da comunidade para a sua efetivação e manutenção.

Entretanto, é possível promover o acesso desse grupo às atividades de formação e de organização de redes de economia solidária na região e à política pública municipal da assistência social, com seus programas de qualificação profissional no âmbito da inclusão produtiva, além da interlocução com experiências dessa natureza em cidades próximas e da inscrição do projeto no Cadastro de Iniciativas de Inclusão Social pelo trabalho da Coordenação Nacional de Saúde Mental, do Ministério da Saúde.

Além disso, é de fundamental importância promover a interlocução entre as Secretarias de Saúde, de Assistência Social e de Educação e de Trabalho, dentre outras, no âmbito das três esferas de governo (federal, estadual e municipal), na construção de políticas públicas intersetoriais, na constituição de associações de usuários, familiares e trabalhadores, no acompanhamento das incubadoras de cooperativas populares das Universidades, bem como de outras ações de extensão e/ou pesquisa, além da concretização de instrumentos de finanças solidárias, da realização de ações de formação, da constituição de fóruns e da realização de feiras de economia solidária.

Vimos, então, que, na articulação saúde mental e economia solidária, os sujeitos da experiência da loucura são capazes de avaliar e de executar coletivamente sua atividade produtiva em uma perspectiva autogestionária. Diante da importância do trabalho, tanto na saúde mental quanto na economia solidária, ressalta-se o significado desse na vida do ser humano que lida com o sofrimento psíquico, pois existe a possibilidade da estruturação de um saber imbricado com o fazer do trabalho. 
Além disso, esse é um meio de inserção na sociedade, um modo de se lidar melhor com o sofrimento e com o que este representa em sua vida, um meio de estar em contato com outras pessoas facilitando igualmente a troca de experiências e o combate à cronificação, evitando possíveis crises por causa do sofrimento psíquico.
Por fim, podemos afirmar que o trabalho remunerado, não necessariamente assalariado, proporciona o direito de produzir, de reproduzir e de prospectar a vida; assim, promove autonomia, cidadania, emancipação e produção de outros modos de subjetivação. 


\section{Márcia Campos Andrade}

Doutoranda em Psicologia pela Universidade Estadual Paulista Júlio de Mesquita Filho e professora da Universidade Estadual de Maringá, Maringá - PR - Brasil.

E-mail: maringa2008@yahoo.com.br

\section{Maria Aparecida de Moraes Burali}

Doutoranda em Psicologia pela Pontifícia Universidade Católica de São Paulo e professora da Universidade Estadual de Maringá, Maringá - PR - Brasil.

E-mail: mbburali@yahoo.com.br

\section{Aline Vida}

Psicóloga formada pela Universidade Estadual de Maringá, Maringá - PR - Brasil.

E-mail: li_vida@hotmail.com

\section{Michely Balladeli B. Fransozio}

Psicóloga formada pela Universidade Estadual de Maringá, Maringá - PR - Brasil.

E-mail: michelyballadeli@gmail.com

\section{Raquel Zavatin dos Santos}

Psicóloga formada pela Universidade Estadual de Maringá, Maringá - PR - Brasil.

E-mail: raquel_zavatin@yahoo.com.br

\section{Endereço para envio de correspondência:}

Rua Pioneiro Alberto Biazon, 692, Vila Marumby. CEP: 87050-310. Maringá, PR

Recebido 21/03/2012, 1a Reformulação 12/11/2012, Aprovado 29/11/2012. 


\section{Referências}

Amarante, P., \& a Torre, E. H. (2001). Protagonismo e subjetividade: a construção coletiva no campo de saúde mental. Ciência \& Saúde Coletiva, 6(1), 73-85.

Andrade, M. C. (2010). O trabalho como interlocutor entre a saúde mental e economia solidária. In F. Hashimoto, (Org.), Psicologia e trabalho: desafios e perspectivas (pp. 241-266). Assis, SP: UNESP.

Arruda, M. (2003). Trabalho emancipado. In A. D. Cattani (Org.), A outra economia (pp. 260-268). Porto Alegre: Veraz Editores.

Lei $n^{\circ}$ 9.867, de 10 de novembro de 1999. (1999, 11 novembro). Dispõe sobre a criação e o funcionamento de Cooperativas Sociais, visando à integração social dos cidadãos conforme especifica. Diário Oficial da União, Seção 1.

Brasil. Ministério da Saúde. (2002). III Conferência Nacional de Saúde Mental. Relatório Final. Brasília, DF: Ministério da Saúde.

Brasil. Ministério da Saúde e Organização Pan Americana de Saúde. (2005a). Reforma psiquiátrica e política de saúde mental no Brasil. Conferência Regional de Reforma dos Serviços de Saúde Mental: 15 anos depois de Caracas. Brasília, DF: Ministério da Saúde e Organização Pan Americana de Saúde.

Brasil. Ministério da Saúde. (2005b). Saúde mental e economia solidária: inclusão social pelo trabalho. Brasília, DF: Ministério da Saúde.

Portaria Interministerial $n^{\circ} 383$, de 7 de março de 2005. (2005). Institui o Grupo de Trabalho de Saúde Mental e Economia Solidária e dá outras providências. Brasília, DF: Diário Oficial

Brasil. Ministério da Saúde. (2007). Saúde mental no SUS: acesso ao tratamento e mudança do modelo de atenção. Relatório de Gestão 2003-2006. Brasília, DF: Ministério da Saúde.

Brasil. Ministério da Saúde. (2010a). IV Conferência Nacional de Saúde Mental - Intersetorial. Relatório Final. Brasília, DF: Ministério da Saúde.

Brasil. Ministério do Trabalho e Emprego. (2010b). Conferência Temática de Cooperativismo Social. Caderno Temático. Brasília, DF: Ministério do Trabalho e Emprego.

Costa-Rosa, A. (2008). Intercessões e análises sobre o processo de produção saúde-adoecimento atenção no campo psíquico, num território municipal. Produção de novas tecnologias para o implemento da Atenção Psicossocial no Sistema Único de Saúde. UNESP/Assis. Mimeo.

Deleuze, G. (1972-1992). Conversações. Rio de Janeiro: Editora 34.
Foucault, M. (2003). A história da loucura na idade clássica. São Paulo: Perspectiva.

Guattari, F., \& Rolnik, S. (1986). Micropolíticas: cartografias do desejo. Petrópolis, RJ: Vozes.

Guerra, A. L. C. (2008). Oficinas em saúde mental: percurso de uma história, fundamentos de uma prática. In C. M. Costa, \& A. C. Figueiredo (Orgs.), Oficinas terapêuticas em saúde mental: sujeito, produção e cidadania (pp. 23-57). Rio de Janeiro: Contra Capa.

Lourau, R. (2004). Uma técnica de análise de implicações: B. Malinowvski, diário de etnógrafo (1914-1918). In S. Altoé (Org.), René Lourau: analista institucional em tempo integral (pp.212-223). São Paulo: HUCITEC.

Minayo, M. C. de S. (Org.). (1994). Pesquisa social: teoria método e criatividade. Petrópolis, RJ: Vozes.

Paulon, S. M. (2005). A análise de implicação como ferramenta na pesquisa-intervenção. Psicologia \& Sociedade, 17(3), 18-25.

Passos, I. C. F. (2009). Reforma psiquiátrica: as experiências francesa e italiana. Rio de Janeiro: FIOCRUZ. (Coleção Loucura \& Civilização).

Pichon-Rivière, E. (1988). O processo grupal (3a. ed). São Paulo: Martins Fontes.

Rolnik, S. (2007). Cartografia sentimental: transformações contemporâneas do desejo. Porto Alegre: Sulina; Editora da UFRGS.

Rotelli, F., Leonardis, O., \& Mauri, D. (1994). La empresa social. Buenos Aires: Ediciones Nueva Visión.

Santos, B. S., \& Meneses, M. P. (Orgs.). (2010). Epistemologias do sul. São Paulo: Cortez.

Sawaia, B. (2006). O sofrimento ético-político como categoria de análise da dialética exclusão/inclusão. In B. Sawaia (Org.), As artimanhas da exclusão: análise psicossocial e ética da desigualdade social. Petrópolis, RJ: Vozes.

Singer, P. (2003). Economia solidária. In A. D. Cattani (Org.), A outra economia (pp. 116-124). Porto Alegre: Veraz Editores.

Zambroni-de-Souza, P. C. (2006). Trabalho, organização e pessoas com transtornos mentais graves. Cadernos de Psicologia Social do Trabalho, 9(1), 91-10. 